\title{
Spinal evoked responses recorded from the epidural space in normal and diseased humans
}

\author{
M. R. CACCIA, E. UBIALI, AND L. ANDREUSSI ${ }^{1}$ \\ From the Servizio di Neurofisiopatologia, Ospedale Regionale, Bergamo, Italy
}

SYNOPSIS In 22 subjects, including normal subjects and patients with radicular or spinal cord lesions, the authors studied the spinal evoked responses recorded extradurally after stimulating mixed limb nerves. The responses obtained are discussed with particular reference to the clinical value of the changes in amplitude and latency of the spinal evoked potential with particular lesions.

Spinal evoked potentials from peripheral nerve stimulation have been studied in man by Liberson et al. (1963, 1966) and recently by Cracco (1973) using surface recording, and by Shimoji et al. (1971) recording epidurally and intrathecally.

The purpose of this paper is to describe the results we obtained with needle recording using a superimposing or averaging technique with an analogue instrument which has 200 ordinates. The outstanding features of our technique, we believe, are its rapid execution, the fact that it is well tolerated by patients, and its ease of use in clinical practice.

\section{METHOD}

The evoked action potential was recorded from the epidural space at the cervical or dorsal level using a flexible Teflon cannula that measured $1.2 \mathrm{~mm}$ in diameter and was equipped with a hollow steel stylet $1 \mathrm{~mm}$ in diameter projecting $2.2 \mathrm{~mm}$ from the end of the cannula; it was the stigmatic pole of the recording system. The needle was inserted manually into the intervertebral space along the median plane under radiological image intensifier control with lateral and sagittal projections; it was withdrawn a few millimetres after the appearance of the first drops of cerebrospinal fluid (Fig. 1).

The indifferent electrode consisted of an ordinary

1 Visiting fellow from Neurosurgery Unit, Istituto Giannina Gaslini per le Malattie dell'Infanzia, Genova, Italy.

(Accepted 5 May 1976.)

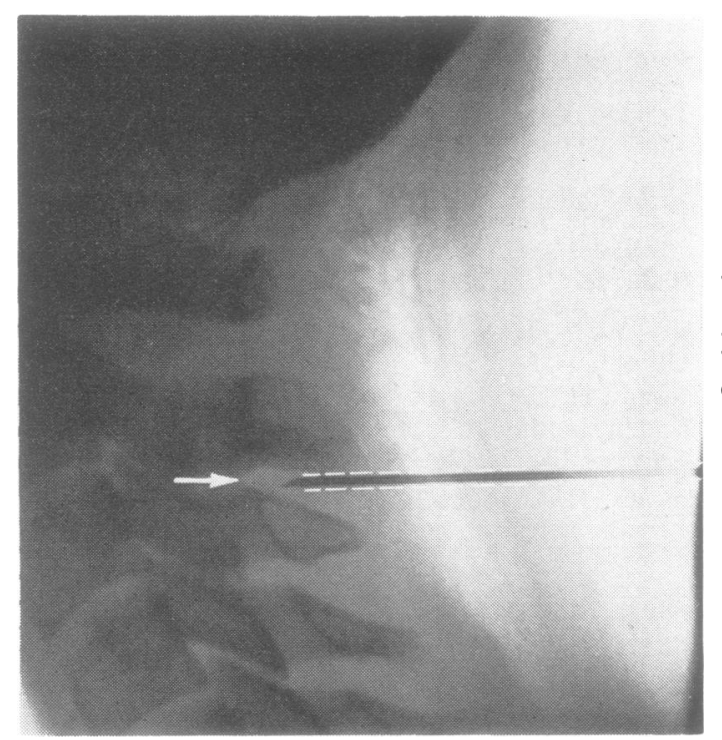

FIG. 1 SEP recording needle withdrawn a few millimetres from the dura mater at $\mathrm{C2}-\mathrm{C} 3$ intervertebral space. Arrow: level of the dura mater; dotted line: Teflon-cannula outline.

EEG recording needle inserted in the skin of the back in the most suitable position for reducing the electrocardiogram, which was particularly evident in the case of dorsal recording.

The signal was amplified, averaged, and recorded with a Modular Electrophysiological System (MS6) of Medelec Limited, Woking, England (preamplifier PA 467/15, amplifier AA6 MK2, display and record- 
ing unit DFO6-N6, signal averaging AVM6 at 200 ordinates) and photographed on a Tektronix storage oscilloscope.

An optimal response was obtained by analysing 50 signals in linear function with $20 \mathrm{~ms}$ of gate analysis (Fig. 2) or 5 to 10 signals in exponential function.

In certain favourable cases, when the paravertebral muscles were relaxed the potential was easily obtained using a single superimposing technique on the storage oscilloscope (Fig. 3).

The EMG artefacts, which were also analysed by averaging, had no major effect on the latency (measured to first negative peak) or shape of the evoked response, as shown by recordings performed before and after curarisation (Fig. 4). Amplitude was measured peak to peak.

Stimulation was carried out by bipolar surface electrodes applied over the popliteal nerves for recordings from the dorsal cord, and over the nerves at the wrist for cervical recordings. The popliteal, median, and at times the ulnar nerve were stimulated on both sides with square wave electric stimuli lasting 50-100 $\mu$ s from two Medelec NS6 and NT6 stimulators which also triggered the oscilloscope beam. In some cases the nerves were also stimulated synchronously on both sides.
Bilateral stimulation produced a response with clearer resolution but the amplitude was not markedly different from the unilateral spinal evoked potential in normal subjects, never more than $5-7 \%$ greater than the unilaterally evoked potential (Fig. 5).

\section{SUBJECTS}

The 22 subjects studied were divided into three groups:

1. Normal Six cases: three males and three females (13 recordings), mean age 38.5 years with range of $16-57$ years.

2. Radicular lesions Eight cases: five males and three females (16 recordings), mean age 39.8 years with range of 24-60 years. ${ }^{2}$

3. Spinal cord lesions Eight cases: five males and three females (17 recordings), mean age 45.5 years with range of 29-56 years. ${ }^{2}$

To simplify the correlations of these preliminary data, we have considered only patients without mixed lesions-that is, myeloradicular.

NORMAL SUBJECTS There were six normal volunteers; in three of them the examination was performed under general anaesthesia and curarisation during orthopaedic surgery. In these subjects

A

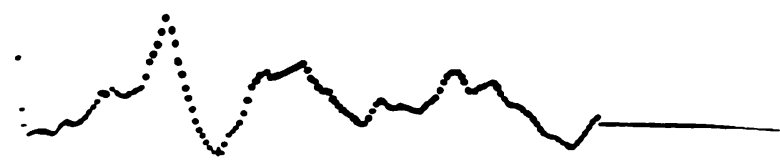

B
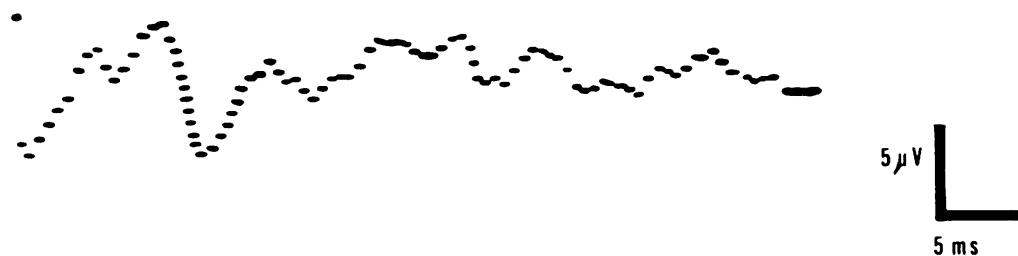

FIG. $2 A$ : SEP in normal subject analysing 50 signals in linear function. Post-analysis delay: $20 \mathrm{~ms}$. B: SEP recorded after 10 signals exponentially analysed. Post-analysis delay: $30 \mathrm{~ms}$. (In all Figures unless otherwise stated, relative negativity of stigmatic electrode gives downward deflection.)

\footnotetext{
IIn all these subjects no radiological abnormalities were found by Pantopaque myelography.
} 

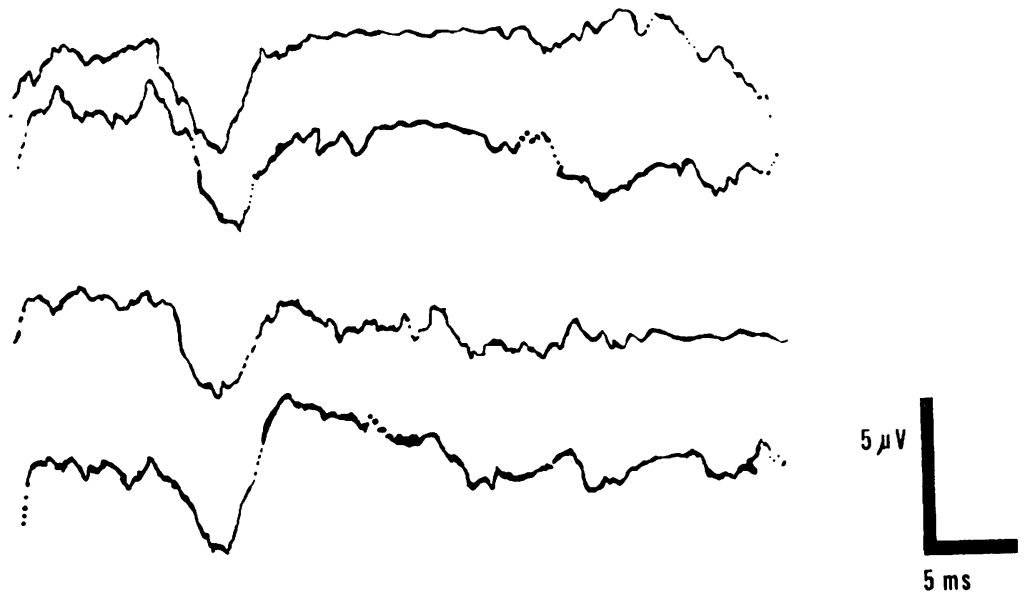

FIG. 3 Normal volunteer: four non-averaged single sweeps recorded from T7-T8 intervertebral space stimulating left $(A)$ and right $(B)$ side

A

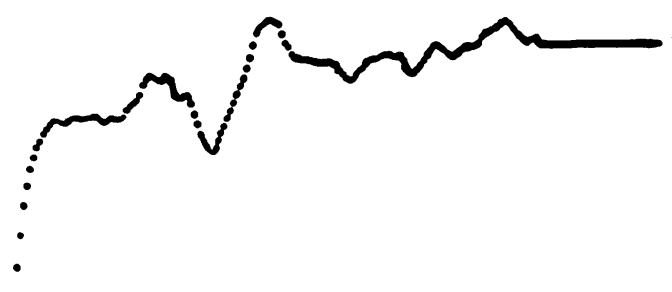

B

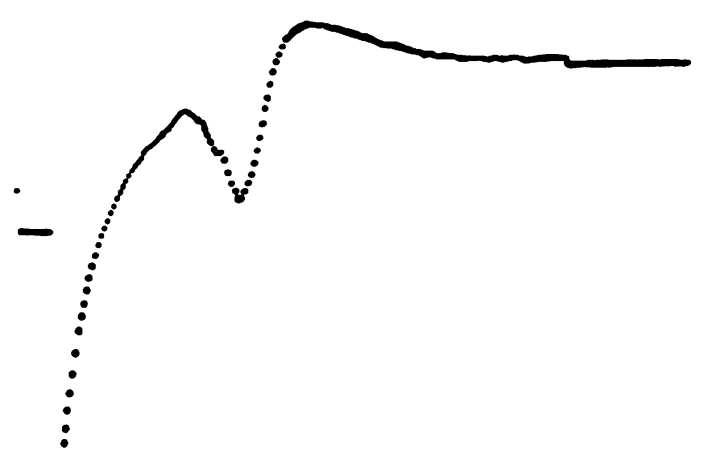

C

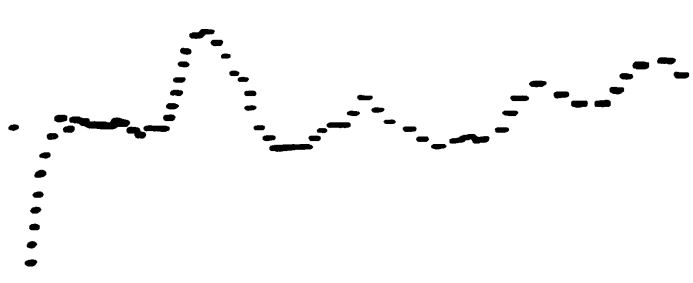

FIG. 4 SEP from two normal subjects recorded from T9-T10 intervertebral space before $(A)$ and after curarisation $(B)$. The same, recorded from C4-C5 interspace before $(C)$ and after $(D)$ curarisation. (Relative negativity upward in $(C)$ and $(D)$. 
A
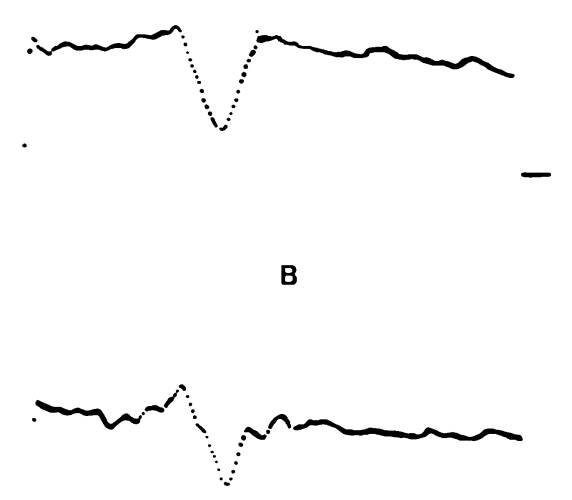

C

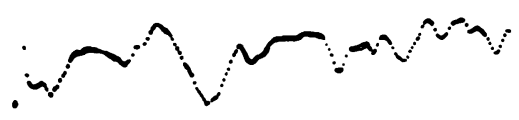

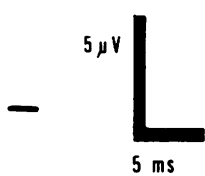

FIG. 5 Normal subject. A: SEP recorded from $C 3-C 4$ intervertebral space stimulating median nerve of both sides. $B$ and $C:$ the response is recorded stimulating the nerve at the right and left side respectively.

the spinal evoked response was recorded from the cervical segments between $\mathrm{C} 3$ and $\mathrm{C} 5$, while the thoracic segments were studied at the T9/10 intervertebral level. One subject was studied at both a cervical and thoracic level with curarisation. We found no significant variations in the amplitude and latency of the responses evoked at different cervical levels and therefore these were grouped for statistical homogeneity in a single figure.

SUBJECTS WITH UNILATERAL RADICULAR LESIONS In five patients the arm was the only involved limb. In two of these the lesion was caused by trauma, while in three other cases a radiculo-neuritis involving the limb-girdle muscles was present. All the recordings were made at C3-C5 segmental levels.

Of the remaining subjects one suffered from sciatica after the infiltration of the anaesthetic, another from a T12-L1 post-arachnoiditic radiculopathy, and the last from a root lesion after an $\mathrm{L} 1$ vertebral body fracture. Recordings in these cases were made from T9-T10 intervertebral levels.

SUBJECTS WITH SPINAL CORD LESIONS This group included:

1. Acute tranverse myelitis One case of syphilitic flaccid paraplegia with an upper sensory level of hypaesthesia at T5 dermatome (recording levels were at T2-T3 and T9-T10 intervertebral spaces).

2. Landry type of acute ascending myelitis A case of flaccid tetraparesis (recording levels were at T6-T7 and L1-L2 intervertebral spaces.

3. Cervical spondylotic myelopathy A case of tetraparesis without clear-cut sensory level associated with severe diffuse cervical spondylosis (two recording levels at $\mathrm{C} 4-\mathrm{C} 5$ and $\mathrm{T} 8-\mathrm{T} 9$ intervertebral spaces.

4. Chronic compressive myelopathy One case of Pott's disease located from C3 to C5 vertebrae with monoparesis of the upper limb and lower spastic paraparesis with sensory disturbances (recording level at C4-C5 and T9-T10 intervertebral spaces).

5. Spinal cord 'systemic' lesions One case of multiple sclerosis with paraparesis (recording level: T7-T8 intervertebral space), one case of Erb-Charcot spinal palsy with severe lower limb paraparesis (recording levels: C3-C4 and T9-T10 intervertebral space), and one case of spastic paraparesis in Von Recklinghausen's disease without radiological abnormalities (recording level: T8-T9 intervertebral space).

\section{RESULTS}

NORMAL SUBJECTS At cervical level the parameters of the evoked potentials from stimulation at the wrist were as follows:

The mean amplitude $( \pm S E)$ of the evoked potentials was $9.0 \pm 1.0 \mu \mathrm{V}$; the mean latency was $9.6 \pm 0.4 \mathrm{~ms}$. The propagation velocity, in relation to the mean distances between stimulation and recording points $(67.5 \pm 1.2 \mathrm{~cm})$ was $70.3 \pm 3.8 \mathrm{~m} / \mathrm{s}$ (Table 1). The evoked potentials under basal conditions and curarisation did not prove to be significantly different in three cases.

The above results do not include the responses obtained in a subject at $\mathrm{C} 4-\mathrm{C} 5$ intervertebral level with stimulation of the median nerve at the elbow. A $3.0 \mu \mathrm{V}$ action potential was obtained from the right arm and $2.5 \mu \mathrm{V}$ from the left at $5.5 \mathrm{~ms}$ latency; 78 and $80 \mathrm{~m} / \mathrm{s}$ propagation velocity respectively.

At the thoracic level we studied two normal 
T A B L E $1 *$

NORMAL SUBJECTS (STIMULATION AT WRIST)

\begin{tabular}{lcc}
\hline & Cervical & Thoracic \\
\hline Amplitude $(\mu \mathrm{V})$ & $9.0+1.0$ & 15.0 \\
Latency $(\mathrm{ms})$ & $9.6+0.4$ & 12.7 \\
Distance $(\mathrm{cm})$ & $67.5+1.2$ & 74.3 \\
Propagation velocity $(\mathrm{m} / \mathrm{s})$ & $70.3 \pm 3.8$ & 58.5 \\
\hline
\end{tabular}

* The Table does not include a normal subject stimulated at the median nerve at the elbow recorded from C4-C5 intervertebral space in whom the evoked potential was only $3.0 \mu \mathrm{V}$ on the right and $2.5 \mu \mathrm{V}$ on the left, with $5.5 \mathrm{~ms}$ latency and a $78 \mathrm{~m} / \mathrm{s}$ and $80 \mathrm{~m} / \mathrm{s}$ propagation velocity respectively.

patients, one curarised. From the uncurarised subject we obtained a spinal evoked potential of $8.0 \mu \mathrm{V}$ from the right and $7.0 \mu \mathrm{V}$ from the left at $12 \mathrm{~ms}$ latency. With bilateral synchronous stimulation, the response was $9.0 \mu \mathrm{V}$ of equal latency. The propagation velocity was $65.8 \mathrm{~m} / \mathrm{s}$.

From the curarised subject, with unilateral stimulation the evoked potential was $30 \mu \mathrm{V}$ amplitude, at $14 \mathrm{~ms}$ latency with a $48 \mathrm{~m} / \mathrm{s}$ conduction velocity.

RADICULAR LESIONS For this type of lesion, it seemed useful to compare the data obtained from the healthy side with those from the impaired one as shown in Table 2 . The amplitude, invariably lower on the impaired side, proved to be the most significant parameter. No significant differences were observed between the two sides for the latency and the shape of the potential.

In a case of acute radiculitis it was possible to pinpoint the proximal location of the lesion on the basis of the parameters of the median nerve

TA B LE 2

RADICULAR LESIONS

\begin{tabular}{|c|c|c|}
\hline & Healthy side & Impaired side \\
\hline \multicolumn{3}{|l|}{ Cervical } \\
\hline Amplitude $(\mu \mathrm{V})$ & $5.2+0.7$ & $2.75 \pm 0.7$ \\
\hline Latency (ms) & $10.4+1.3$ & $10.3 \div 1.98$ \\
\hline Distance $(\mathrm{cm})$ & $67.2 \pm 1.7$ & $67.1=1.9$ \\
\hline Propagation velocity $(\mathrm{m} / \mathrm{s})$ & $64.7+8.8$ & $65.5=12.2$ \\
\hline \multicolumn{3}{|l|}{ Thoracic } \\
\hline Amplitude $(\mu \mathrm{V})$ & $\begin{array}{l:l}6.8 & 1.4 \\
\end{array}$ & $4.3=0.66$ \\
\hline Latency (ms) & $10.4 \pm 0.9$ & $11.8 \pm 1.0$ \\
\hline Distance $(\mathrm{cm})$ & $65.0 \perp 4.4$ & $65 \quad 4.4$ \\
\hline Propagation velocity $(\mathrm{m} / \mathrm{s})$ & $60.4+3.5$ & $55.5 \pm 1.5$ \\
\hline
\end{tabular}

sensory nerve action potential with stimulation at the axilla and at the wrist (Fig. 6).

In a case of limb-girdle neurogenic muscular atrophy of the right arm with hypaesthesia in the C8-T1 territory, we did not obtain a spinal evoked potential by stimulating the right ulnar nerve and recording from C4-C5 interspace, whereas a response of $3.0 \mu \mathrm{V}$ and of normal latency was found on the contralateral side (Fig. 7). The parameters of the right ulnar sensory nerve action potential at the wrist and the elbow were normal.

SPINAL CORD LESIONS (Table 3) 1. From the subject with syphilitic flaccid paraplegia a spinal evoked potential of $20 \mu \mathrm{V}$ amplitude was obtained at T9-T10 intevertebral space with stimulation of the right leg, and of $24 \mu \mathrm{V}$ with the left while the latencies were both $10 \mathrm{~ms}$, giving a propagation velocity of $74 \mathrm{~m} / \mathrm{s}$ on the right and $72 \mathrm{~m} / \mathrm{s}$ on the left. No response was obtained when recording at T2-T3 intervertebral space (Fig. 8).

2. In the patient with ascending flaccid tetraparesis, the study at two levels, L1-L2 and T6-T7 interspaces, showed no evoked response with stimulation of the popliteal nerves.

3 . In the patient with cervical spondylotic myelopathy without a definite sensory level, ? recording at the level of $\mathrm{C} 4-\mathrm{C} 5$ intervertebral space with stimulation of the median nerve at the wrist produced a spinal evoked potential of $17 \mu \mathrm{V}$ amplitude from the right and $16 \mu \mathrm{V}$ from the left with $9.5 \mathrm{~ms}$ latency bilaterally $(73.5 \mathrm{~m} / \mathrm{s})$. Stimulating the ulnar nerve at the wrist we obtained a spinal evoked potential of $8.0 \mu \mathrm{V}$ amplitude from the right and $7.0 \mu \mathrm{V}$ from the left with $10.5 \mathrm{~ms}$ latency on both sides $(66 \mathrm{~m} / \mathrm{s})$. Stimulating the popliteal nerves bilaterally and recording from $\mathrm{C} 4-\mathrm{C} 5$ and from T8-T9 intervertebral spaces we failed to obtain a response.

4. In the patient with Pott's disease at C3-C5 vertebrae, recording from $\mathrm{C} 4-\mathrm{C} 5$ interspace and simulating the median nerve, the spinal evoked potential was $8.0 \mu \mathrm{V}$ amplitude from the right and $7.5 \mu \mathrm{V}$ from the left with $8.0 \mathrm{~ms}$ latency bilaterally. The propagation velocity was 82 and $80 \mathrm{~m} / \mathrm{s}$ respectively. Recording from T9-T10 interspace and stimulating the sciatic nerve we obtained a response of $3.0 \mu \mathrm{V}$ from the right, and $2.4 \mu \mathrm{V}$ from the left with 11 and $10.5 \mathrm{~ms}$ latency 
A

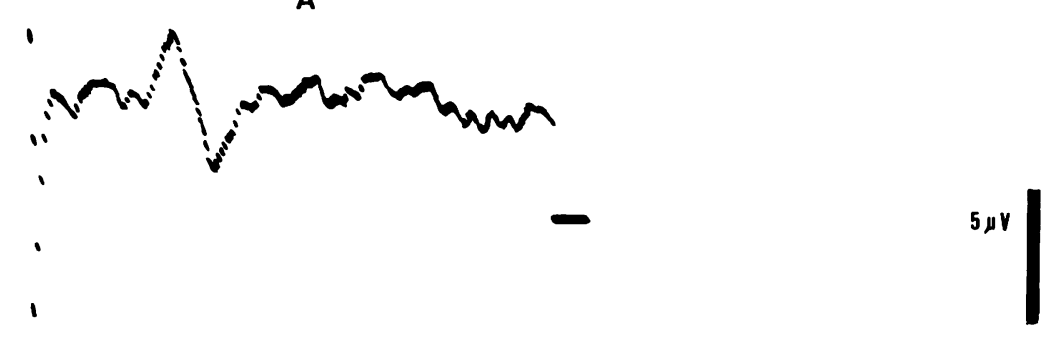

B

1
C

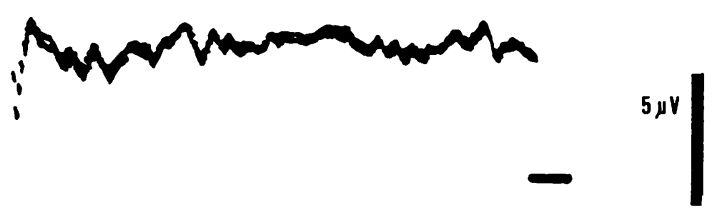

$\mathbf{E}$
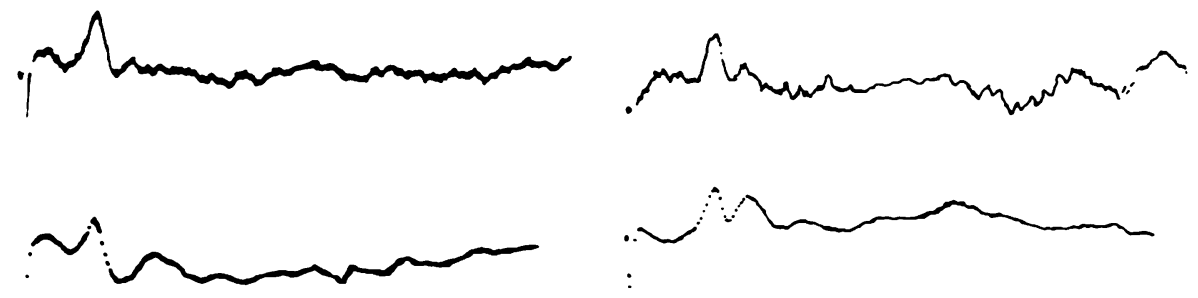

$\mathbf{F}$

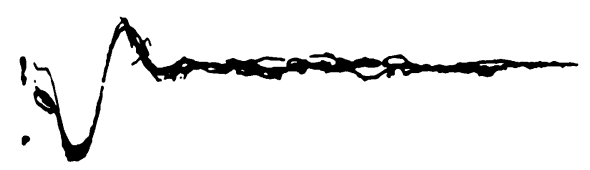

$50 \mu \mathrm{V}$

FIG. 6 Case of acute radiculitis with involvement of the right limb-girdle muscles. A: SEP from C3-C4 interspace after stimulating the median nerve bilaterally. B: Stimulating the left median. C: Stimulating the right median. D: SEP recorded from the ieft axilla (upper trace: averaged; lower trace: not averaged). E: From the right axilla (lower trace: averaged; upper trace: not averaged). F: SEP from the right wrist. (Relative negativity upward in $D$ and $E$.) 


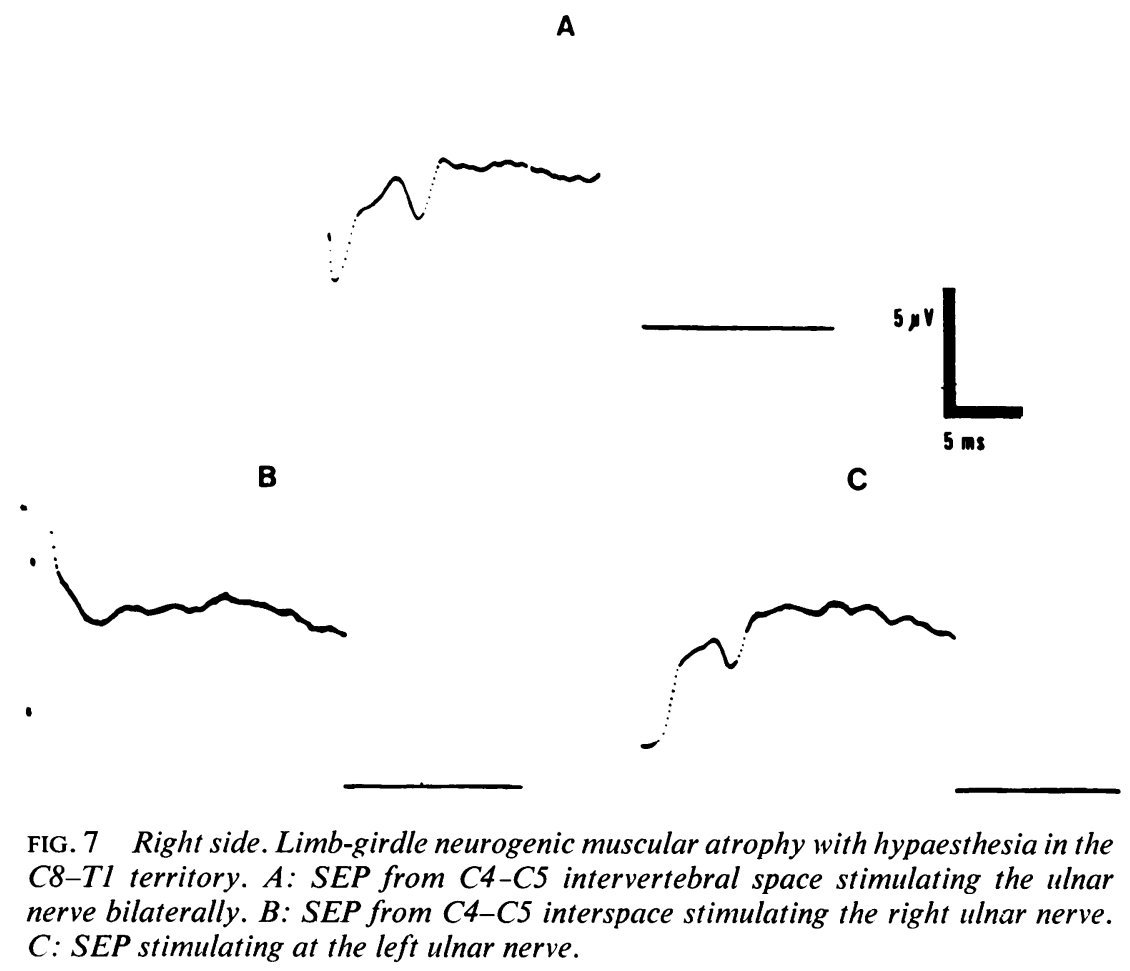

and a propagation velocity of 62.5 and $65.5 \mathrm{~m} / \mathrm{s}$ respectively. In the case of cervical hydromyelia, recording at $\mathrm{C6}-\mathrm{C} 7$ intervertebral space and stimulating the median nerve at both the right and left wrist, we could not obtain a spinal evoked potential.

5. In the group of 'systemic' myelopathies, the responses obtained with single and double stimulation from T7-T8 intervertebral space in a case of multiple sclerosis were 1.5 and $3.3 \mu \mathrm{V}$ respectively, markedly less than our normal thoracic values, with $10 \mathrm{~ms}$ latency at $72.5 \mathrm{~cm}$ distance; in a case of Recklinghausen's disease the responses were 14 and $15 \mu \mathrm{V}$ respectively with 7.0 and $6.0 \mathrm{~ms}$ latency at $63 \mathrm{~cm}$ distance, not significantly different from normal.

In the patient with the Erb-Charcot paraparesis (Fig. 9), however, bilateral stimulation evoked a response with an amplitude twice $(7.0 \mu \mathrm{V})$ that with unilateral stimulation $(4.0 \mu \mathrm{V})$ at the cervical, $10 \mu \mathrm{V}$ and $4.0 \mu \mathrm{V}$ respectively at the thoracic level; with 10-11 ms of latency (68-65 $\mathrm{cm})$, and $59-68 \mathrm{~m} / \mathrm{s}$ propagation velocity cervically and 6 to $10 \mathrm{~ms}(63-72 \mathrm{~cm})$ and $72-100$ $\mathrm{m} / \mathrm{s}$ propagation velocity dorsally.

\section{DISCUSSION}

The spinal evoked potential observed with extradural recordings in our normal subjects proved to be easily measurable, unlike the surface recording by Cracco (1973), and even in some cases (when the degree of muscular relaxation permitted) without averaging techniques. They also appear to be more easily differentiated from the noise level than those obtained by Shimoji $e t$ al. (1971) with a similar technique to our own. In almost all cases the shape proved to be a simple triphasic potential in which the initial rise was never larger than $1.0 \mu \mathrm{V}$ and negative in polarity. In only a few recordings did we observe an initial positive spinal evoked potential polarity, presumably due to some change of the tissue impedance near the recording point. Regarding the parameters of the normal spinal evoked potential, we found good correspondence of 
T A B L E 3

SYSTEMIC MYELOPATHIES

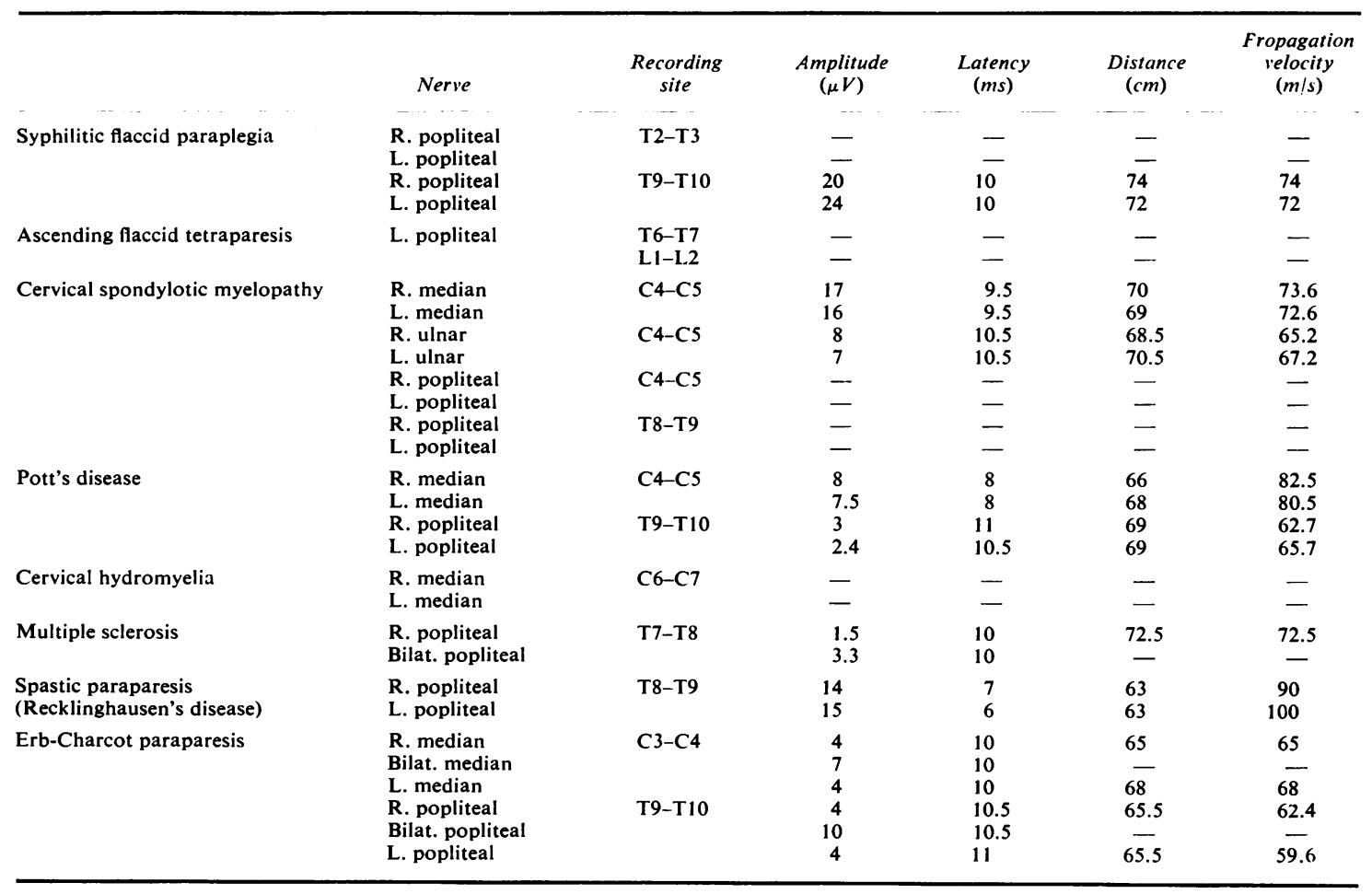

values when comparing the right and left side, with particular reference to the values of the propagation velocity which were very close to those obtained by Cracco (1973).

The nature of the spinal evoked potential has been thoroughly analysed recently by Happel et al. (1975) in the cat. From our studies we accept the suggestion that the first part of the spinal evoked potential may be cutaneous in origin but we believe that at least $60 \%$ of the potential is produced by components from the spinal afferent pathways because of the gross reduction in the amplitude in the cases of transverse spinal cord lesions. Polyphasic long latency late components as described by Happel et al. (1975) were not observed in our responses, presumably because of the low power analysis of the analogue unit employed by us.

For better clinical evaluation of changes in the spinal evoked potential, we compared the potential from the healthy side with that from the impaired limb in our cases of unilateral root lesions. In these cases the amplitude of the spinal evoked potential was the only parameter significantly changed on the side of the radicular impairment, at both cervical and thoracic levels, while the propagation velocity of the response of the still excitable fibres (probably cutaneous) was never found to change significantly. In some cases the evoked potential was studied at peripheral points in addition to the epidural one, and it was possible to 'circumscribe' the lesion in the extraspinal pathways and in certain cases to confirm the proximal level of the lesion without involvement below Erb's point on the brachial plexus. In these cases the reduction or abolition of the spinal evoked potential confirmed the amplitude to be the parameter of most clinical value.

Within the group of myelopathy cases, it was interesting to compare those with a massive involvement (inflammatory) of the spinal cord, 

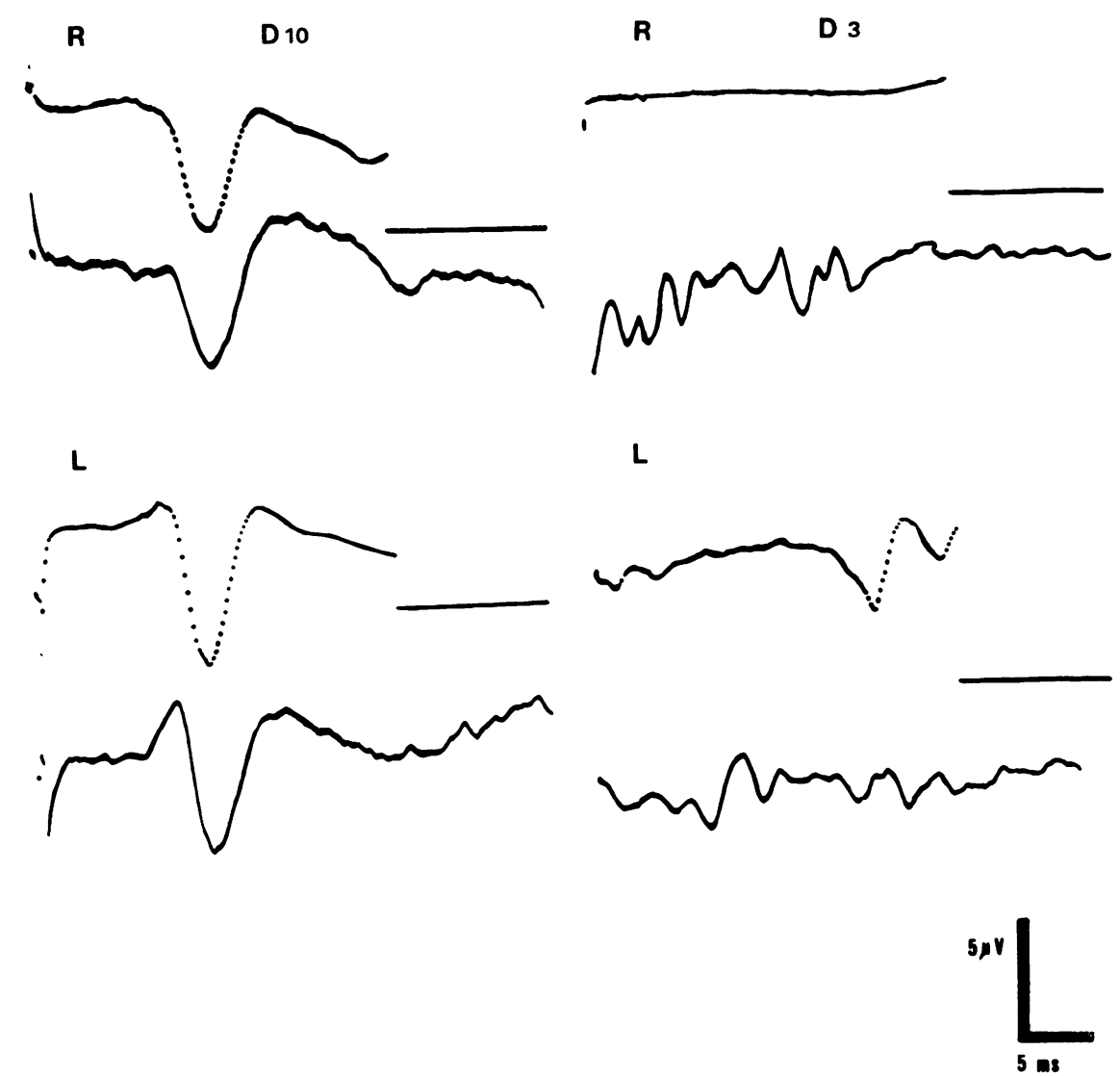

FIG. 8. Paraplegia in acute myelitis. RLT10: SEP recorded from T9-T10 intervertebral space stimulating the right and left sciatic nerve. RLT3: no response from T2-T3 recording site stimulating the right and left sciatic nerves. Upper traces: averaged responses. Lower traces: non-averaged responses.

where the spinal evoked potential was invariably absent above the lesion, with those due to 'extrinsic' compression-that is, Pott's diseasewhere the response showed normal amplitude and propagation velocity at or below the level of the lesion while the potential recorded above was present but of markedly lower amplitude.

On the other hand, the normal spinal evoked potential obtained in all the cases of noncompressive systemic myelopathies seems to underline even more clearly the good clinical value of a study of the evoked potential amplitude in differentiating cases of compressive and noncompressive spinal cord lesions.
However, one of the cases of systemic myelopathy (spastic spinal paralysis) deserves special attention because of the different behaviour of the spinal evoked potential with the synchronous bilateral stimulation compared with the unilateral response. The amplitude was more than twice that of the potential evoked from one side only, suggesting a functional involvement of excitability of the sensory pathways induced by the 'systemic' disease.

The authors are very indebted to Dr Malcolm J. Campbell for criticism and help in the preparation of the manuscript. 


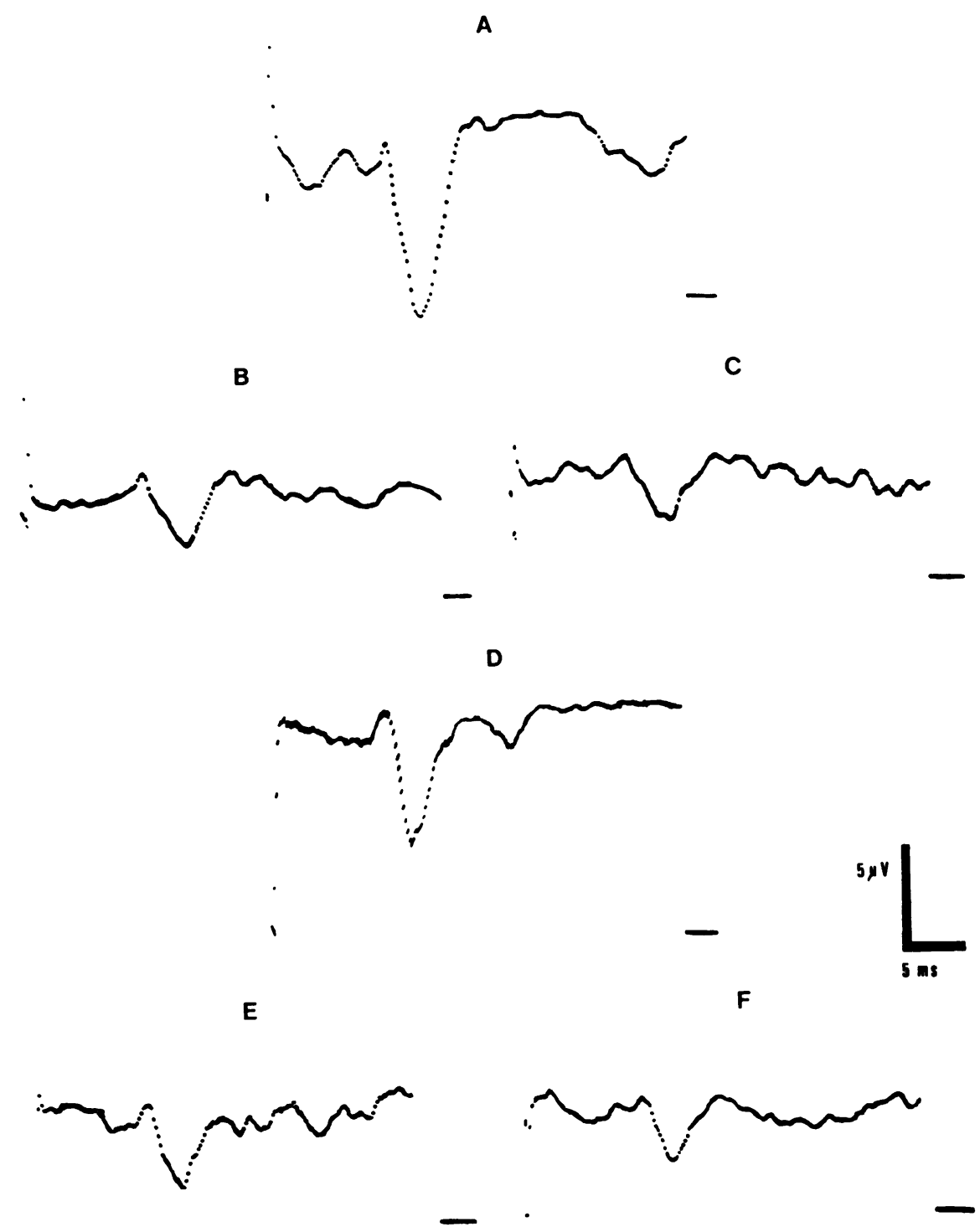

FIG. 9 Erb-Charcot spinal palsy. A-C: SEP recorded from T9-T10 intervertebral space. A: bilateral stimulation. B: Left internal popliteal nerve stimulation. $C$ : right internal popliteal nerve stimulation. $D-F$ : SEP recorded from C3-C4 interspace. $D$ : bilateral stimulation of the median nerve. E: stimulation of the left median. $F$ : stimulation of the right median nerve. Note the difference in amplitude between bilateral and one-sided stimulation. 


\section{REFERENCES}

Cracco, R. Q. (1973). Spinal evoked response: peripheral nerve stimulation in man. Electroencephalography and Clinical Neurophysiology, 32, 623-629.

Happel, L. T., Leblanc, H. J., and Kline, D. G. (1975). Spinal cord potentials evoked by peripheral nerve stimulation. Electroencephalography and Clinical Neurophysiology, 38, 349-354.

Liberson, W. T., Gratzer, M., Zales, A., and Wrabinsky, (1966). Comparison of conduction velocities of motor and sensory fibers determined by different methods. Archives of Physical Medicine and Rehabilitation, 47, 17-23.

Liberson, W. T., and Kim, K. C. (1963). Mapping evoked potentials elicited by stimulation of the median and peroneal nerves. Electroencephalography and Clinical Neurophysiology, 15, 721.

Shimoji, K., Higashi, H., and Kano, T. (1971). Epidural recording of spinal electrogram in man. Electroencephalography and Clinical Neurophysiology, 30, 236-239. 